\title{
Una trayectoria feminista. Entrevista a Graciela Morgade
}

\section{Deborah Daich y Virginia Cano}

Graciela Morgade es Doctora en Educación (UBA), Master en Ciencias Sociales y Educación (FLACSO) y Licenciada en Ciencias de la Educación (UBA). Docente de grado y posgrado, es también investigadora y especialista en Educación Sexual Integral con enfoque de Género y Derechos Humanos. Fue la primera mujer votada como decana en la Facultad de Filosofía y Letras de la UBA, y también nuestra primera decana feminista.

Nos encontramos en su despacho del Ministerio de Educación de la Nación, donde se desempeña actualmente como Subsecretaria de Participación y Democratización Educativa. Siempre generosa, nos recibió este febrero de 2020 para compartir con nosotras algo de su historia y su trayectoria intelectual, biográfica y política.

Recuperar la trayectoria de nuestras colegxs, compañerxs y maestrxs resulta una tarea fundamental para la construcción siempre colectiva de nuestras memorias feminista y disidentes. Graciela Morgade es, a nuestro entender, una pieza clave en el ejercicio de desplegar una política de la memoria institucional y académica. 
Nos gustaría empezar preguntándote, ¿cuándo considerás que te hiciste feminista? 0 , ¿cuándo te nombraste a vos misma feminista?

GM: Lo tengo bastante pensado. De hecho, lo escribí en el "Prólogo" de mi tesis de maestría en 1992. En 1981 era maestra -estudié el profesorado de educación primaria-, trabajaba en una escuela y estudiaba Ciencias de la Educación al mismo tiempo. Un día vino una antropóloga, Graciela Batallán, y nos invitó a hacer investigación de nuestra propia práctica, en la escuela donde trabajaba (que era una escuela cooperativa en la provincia de Buenos Aires). Allí fuimos todas las compañeras, todas las que éramos maestras en ese grupo. En años de dictadura, esto era una oferta de liberación intelectual: un análisis de nuestra propia práctica. Y yo tenía una mirada de docente, una docente que investiga, sobre la práctica docente. La investigación de la práctica es la manera de formarse permanentemente.

Después, estuve en Chile, con mi entonces marido, y quedé embarazada usando DIU. Entonces nos preguntamos: “¿qué hacemos?” y dijimos: "bueno, seguimos adelante". Yo hubiera abortado si lo hubiera decidido, ya había tenido un aborto, pero quise seguir adelante. El embarazo y la maternidad me pegaron de un modo particular... creo que siempre es difícil ser madre. Cuando estaba en mi casa amamantando, y estaba en esa domesticidad del primer tiempo, me quería ir. Y cuando estaba en el trabajo, quería volver. En esa sensación de desgarramiento interno empecé también a pensar, a reflexionar. Ya había tenido unas amigas feministas en Chile, pero creo que fue esa experiencia personal la que me terminó de hacer ver -o me hizo sentir-que hay algo en la docencia relacionado con la condición femenina. La docencia como trabajo de mujeres ...algo debía estar impactado por esa condición. Bueno, mi hija nació en 1985 y en 1986 me presenté, con Graciela Batallán como directora, a mi primera beca del Conicet: "La docencia como trabajo femenino" (que inicié en 1987). Lo tengo bastante identificado como momento, y muchas veces dije que mi trabajo había sido la posibilidad de elaboración de mi propio conflicto con la maternidad. Yo siempre decía "la suerte que yo tengo es que leo para mi vida". Es muy honesto lo que estoy diciendo.

\section{¿Qué es, para vos, ser feminista?}

GM: Fue cambiando y creo que hay un feminismo para cada momento de la vida; lo digo desde la perspectiva subjetiva. Además, los feminismos fueron cambiando. Yo pasé por una etapa en la que pensaba desde los materialismos dialécticos, los feminismos socialistas, en donde la contradicción de clase era central pero no me terminaban de cerrar porque desde mi perspectiva la contradicción de patriarcado también es determinante. Pensaba mucho en las condiciones materiales de vida, particularmente de las vidas de las mujeres, articulando fuertemente la clase y lo que en ese momento llamábamos sexo-género. En aquel momento se decía: "el género es lo cultural y el sexo es lo biológico". Por eso le digo a los estudiantes que si encuentran un texto mío de los 90, sepan que ahora no pienso eso.

Pero en aquel entonces el feminismo era para mí, sobre todo, una cuestión muy vinculada con el trabajo, con los derechos; en algún sentido, algo más vinculado con lo que se conoce como el feminismo de la igualdad. Con el tiempo, fui deviniendo en feminista de la diferencia y me copé con la necesidad feminista de visibilizar y poner en valor las producciones femeninas; porque trabajé mucho el tema de la docencia que creo que recién ahora, treinta años más tarde, estamos pudiendo sintetizar pensando en la teoría del cuidado. Recuerdo que en aquel momento yo leía a Nel Noddings, que es una docente estadounidense de los años 80-90, que hablaba de la teoría del cuidado, del caring, y pensaba la tarea docente en términos de cuidado. Estaba muy de la mano de aquellas miradas esencialistas, como la de Carol Gilligan, pero había algo en el feminismo de la diferencia que me atrapaba, que me parecía interesante y valioso, que era la lucha por visibilizar y poner en valor lo que hacemos las mujeres, es decir, aquellas identidades históricamente construidas como mujeres (nunca fui biologicista).

Con los años, yo misma fui acompañando, protagonizando y también receptando los debates posestructuralistas y los de las disidencias y todas las formas identitarias no binarias, desde la investigación de la docencia. Ya en 2004, después de casi veinte años trabajando la docencia como trabajo femenino (mi tesis de doctorado fue sobre mujeres que dirigen en la escuela primaria), pensando las temática de los cuerpos y las sexualidades, fueron los feminismos posestructuralistas, las discusiones en torno al binarismo de la categoría género los que me parecieron superadores de aquello que me había fascinado del feminismo de la diferencia y que siempre tenía una especie de halo esencialista e incluso a veces hasta romántico, en el sentido de romantizar las vidas femeninas.

En mi pensamiento, en los últimos años, acompaño mucho algo que siempre estuvo ahí pero que ahora se puede formular y articular más y es la idea contemporánea de pensar que hay feminismos populares. Me interesa esta idea política de los feminismos populares porque, nuevamente, se focaliza en una fuerte relación de las luchas de las clases sociales y la importancia de las bases materiales. Me da la impresión de que en este proceso de pensamiento, en el cual además devine peronista, me re-encuentro con una mirada sobre los derechos, sobre las bases materiales, la 
valoración de lo femenino, el lugar de las mujeres en la construcción de las sociedades, así como la pluralidad de definiciones de lo femenino. En ese sentido, las categorías de los feminismos populares, disidentes, y todas estas articulaciones a la vez, son fundamentales.

\section{¿Esta formación feminista fue extraacadémica?}

GM: Después de esa toma de conciencia posparto, empecé a buscar y conocí a Gloria Bonder - psicóloga, dedicada a temas de educación-y ella fue muy generosa conmigo desde el principio. Recuerdo que me dijo, a modo de ofrecimiento: "esta es mi biblioteca". Y tenía muchísimos libros, muchos en inglés, sobre teoría de género ¡Todas las teorías! Había muchísimo sobre género y educación. Entonces, en 1991, ella me invitó a ser docente del módulo de educación y género de la carrera de Especialización en Estudios de la Mujer que se dictaba en Psicología. Lo que hice fue estudiar un poco sola, pero con beca del Conicet y acceso a estas bibliotecas. Siempre fui estudiosa, tuve ahí una oportunidad muy grande de formarme, mientras también hacía docencia. En mi formación en la Maestría en Ciencias Sociales y Educación de FLACSO tuve la oportunidad de formarme en Ciencias Sociales, no tanto en temas de género que no había demasiado, pero pude también recuperar lo que podría llamar el tiempo perdido de haber estudiado en la dictadura. No quiero dejar de nombrar la creación del Área Interdisciplinaria de Estudios de la Mujer, posteriormente Instituto de Género, porque para mí fue determinante. Y lo fue porque en educación la hegemonía intelectual era el marxismo, es decir, la crítica marxista. Aprendí mucho con otras mujeres, como Silvia Llomovatte, y fui conociendo algunas personas con las que hice contactos intelectuales. Pero en el Área (actual IIEGE) estaban el grupo de las filósofas, las historiadoras, las compañeras de Letras, las de Artes con Ana Amado, que eran fuertes y formidables. Toda esa formación fue casi entre mujeres, así, muy horizontal.

Mi primer seminario de doctorado, me acuerdo, fue con Marita Santa Cruz, sobre género, igualdad, diferencia. Marita Santa Cruz era de las filósofas. Lo que quiero decir es que la facultad fue un espacio determinante, formativo.

Y también una obstinación: en educación era la de género, entre comillas, y en género, era la de educación. En todos lados tenía que andar explicando qué hacía. Pero también tuve una muy importante experiencia en el Ministerio de Educación, entre 1991 y 1995 , con un Programa de Igualdad de Oportunidades para la Mujer (así se llamaba), que dirigía Gloria Bonder, en el marco de las políticas que impulsaba el Consejo Nacional de la Mujer, donde estaba Virginia Franganillo. Esa fue una oportunidad de formación y aprendizaje en temas de educación y género. El programa terminó en el momento en que el Ministerio decidió sacar la categoría "género" de los contenidos básicos comunes, como se llamaba en ese momento a los lineamientos curriculares. Fue cuando la Argentina participó en la conferencia de Beijing en 1995, y desde allí decidió aliarse con el Vaticano, "contra el género". Ahí renunciamos nosotras, pero fueron cuatro años de mucho aprendizaje.

Cabe señalar que mi doctorado no es en género, es en educación y no existía el doctorado en género, pero tenía una perspectiva de género. No es que hice una formación sistemática, porque no había tal cosa. Mis dos maestras fueron Graciela Batallán y Gloria Bonder. Graciela, porque la investigación de la práctica y la mirada antropológica y crítica sobre los procesos sociales y la investigación cualitativa las aprendí con ella y, además, incorporé la convicción de una mirada sobre la docencia como tarea de creación de conocimiento. Y con Gloria aprendí sobre género, educación, política, y el mundo feminista. Ya en 1996 dicté, en Filosofía y Letras y por primera vez, el seminario de “Educación y Género" en Ciencias de la Educación.

Todas estas generaciones no se formaron de manera sistemática, porque no había cómo. Pero son generaciones que lograron insertar la temática académicamente, tu seminario de educación y género, por ejemplo. ¿Considerás que darle legitimidad a la perspectiva fue un proceso arduo? GM: El proceso para mí no fue tan difícil. Y en ese sentido tengo que hacer un reconocimiento. Si bien fuimos oposición [se refiere a la política universitaria], tuve apoyo de dos personas: Edith Litwin y Ovide Menin. Ovide Menin, el director de Ciencias de la Educación, era un tipo muy piola, muy sensible. Abiertamente gay, muy inteligente, muy sensible, radical. Él me dijo en 1991: "Mire Graciela, yo no sé muy bien lo que hace usted, pero a mí me parece interesante", y me dio una dedicación semiexclusiva en el Instituto cuando terminó mi beca del Conicet. Sostuve bastante tiempo esa dedicación, con uñas y dientes, para mover el tema. Edith Litwin, otra radical (lo digo porque la cuestión de la posición política muchas veces atraviesa la política institucional, pero yo fui encontrando interlocuciones de mucho apoyo), me dijo en 1996, "vos hacé la carta, que yo te presento porque a mí me parece que esto es importante". Ella no entendía mucho de qué se trataba, pero le parecía algo valioso. Me acuerdo que yo hice una carta que decía, más o menos, que yo era la octava maravilla. La recuerdo a Edith Litwin diciendo: "no tenés abuela vos, Graciela”. En fin, Edith me apoyó y salió el seminario. En aquel momento yo no tenía un título de doctorado, sí de maestría, y la facultad era muy estricta con las designaciones para el cargo de adjunta para el dictado de seminarios si no tenías el doctorado. Había que 
argumentar muy bien que era un área de vacancia, así que en eso me ayudó Edith. Y bueno, las compañeras del área siempre me ayudaron.

¿Por qué tu equipo no está inserto en lo que antes era el área y ahora es el Instituto?

GM: Fue una decisión política y una decisión explícita. Yo dije: "si nosotras nos vamos de educación, esto no crece más". Incluso cuando algunos de los padres fundadores de los estudios de la Sociología y la Antropología crítica de la educación (me refiero a pedagogos como Michael Apple, u otros como Henry Giroux) hablaban del movimiento feminista en Estados Unidos, esto no pasaba en nuestro contexto. En el marco latinoamericano, Paulo Freire escribe un libro determinante que fue Pedagogía de la esperanza, donde reconoce el movimiento feminista, y le reconoce haberle permitido ver que ese oprimido femenino del que él hablaba en Pedagogía del oprimido, estaba ya allí. Paulo Freire agradece a las feministas que se hubiera abierto la categoría del oprimido, que se veía que no era una categoría internamente homogénea. Los padres fundadores de los estudios críticos de la pedagogía popular lo venían diciendo, pero era tibio en educación. En este contexto, si me iba para el Instituto, esto desaparecía. Esa era mi hipótesis. En ese entonces, era codirectora, con Graciela Batallán como directora, de una línea sobre participación escolar y gestión o conducción de las escuelas, y yo ya ahí estaba trabajando dentro de este UBACyT el recorte de la conducción escolar por parte de mujeres. Pero era lo único que había en el Instituto de Ciencias de la Educación.

Fue una estrategia de intervención institucional.

GM: Sí, tal cual. Fue una estrategia. Tal vez ahora sería distinto. Ahora las compañeras pueden estar en los institutos de las carreras de formación, y también en el Instituto de Género. Siguen siendo decisiones políticas. También creo que, en la facultad, y esto lo digo reflexivamente, el Instituto estuvo visualizado en la dinámica institucional, no diría de la oposición, pero seguro no del riñón del espacio político al que yo pertenecía. Eso me interesa decirlo, para reflexionar sobre quiénes están en un lugar, quiénes conducen. Esas dinámicas atraviesan a esta facultad y también tienen que ver con otras decisiones. Pero eso no incidió en mi propia decisión. Mi idea era quedarme en educación, y construir desde ahí. Estuvo bien, fue acertado. El equipo creció y hoy es Mariposas Mirabal, un colectivo con doctoradas y mastradas, con proyectos de investigación, docencia, extensión, transferencia y militancia. Tremendo equipo. Mi modelo de universidad en acción.
¿Cómo te llaman para la elaboración de los lineamientos de ESI?

GM: Me llamaron a constituir una comisión de especialistas que produjo un documento de base para los lineamientos curriculares. Yo integré esa comisión. Había en ese momento una subsecretaria, Alejandra Birgin, y Juan Carlos Tedesco era ministro. Había muchas personas que me conocían y conocían ya el trabajo que yo venía haciendo, entonces me convocaron como especialista. Se produjo un documento de base, que fue retomado por los equipos técnicos del Ministerio que hicieron los lineamientos. La ley establece la creación del programa, y la conformación de una comisión de especialistas. Esa comisión tenía que producir un documento de base que sirviera para los lineamientos curriculares.

Sabemos que la coyuntura fue difícil y que la palabra género aparecía una sola vez, y lo que nos preguntábamos, sabiendo la historia de este documento porque la has contado muchas veces, ¿cómo ves, hoy, la ESI? ¿Qué debería incorporar en esta nueva coyuntura histórica, política y social?

GM: La pregunta es adecuada, porque debemos preguntarnos si la ley de 2006 hoy responde a lo que le pedimos a la ESI, y la respuesta es que definitivamente no. Pero la Ley de 2006 fue un logro extraordinario que sirvió para concentrar otros anteriores y catalizar una fuerza que fue sosteniendo el mismo proyecto de ESI. Así que me parece que la ley es una producción histórica muy poderosa. Después de la Ley de ESI se votaron muchas otras, el mismo campo se amplió y claramente el texto de la Ley hoy no es suficiente. Cuando se debatió en 2018 la legalización del aborto que finalmente no salió, ahí se presentó un proyecto de modificación de la ESI. En ese proyecto se planteaban algunas de las discusiones que están en la base y que todavía son tensiones. Por ejemplo, la incorporación de la Ley de Identidad de Género y la de Matrimonio Igualitario. Como instrumento político me parece, y voy a hablar ahora como mujer política, a tres días de que el presidente anunció que mandará un proyecto de ley para legalizar el aborto, que no es necesario tocar la ley de ESI, yo no la tocaría. Creo que el Programa Nacional de Educación Sexual Integral vino desplegando y tiene como propósito ampliar el espectro de las temáticas y complejizar los enfoques, sin necesidad de tocar la ley. Según salga la votación de la ley de interrupción voluntaria del embarazo, hay que pensarlo. Estoy pensando pragmáticamente a niveles políticos: si vuelve a no salir la ley de aborto legal, seguro y gratuito, no toquemos la ley de ESI. Sería peor de la que está. 
¿Por qué? Desde tu perspectiva, ¿sería darles fuerza a los antiderechos?

GM: Exacto...

¿Qué temas imaginás que necesariamente debería abordar la ESI hoy?

GM: Tal como están formulados los lineamientos, la ESI no presenta una densidad epistemológica de discusión de los saberes de referencia, así como tampoco presenta una discusión pedagógica vinculada con la pedagogía feminista. Hay un enorme y sistemático silencio sobre la perspectiva de género porque en aquel momento se incluyó hasta donde se pudo. Pienso, por ejemplo, que ocurre a menudo que en las capacitaciones alguien levanta la mano y pregunta “Por qué en los lineamientos curriculares no hablan de infancias trans?"; y yo respondo que en 2006 no teníamos la categoría desarrollada. En aquel entonces decíamos, convencidas, que la identidad sexual y la orientación sexual se definían en la adolescencia. Eso decíamos sobre la base de la psicología, por ejemplo. Obvio que había registros de experiencias distintas, pero no teníamos la categoría. Palabras más, palabras menos, yo respondo que no hablábamos de infancias trans en la academia y tampoco en los movimientos. Había personas, había experiencias, había discusiones, pero no teníamos categorías para hablar de eso.

Las discusiones sobre identidad y orientación sexo-genérica no estaban en la agenda hegemónica e institucional del feminismo.

GM: Exactamente. No estaba en la agenda de los temas habilitados para el debate público, creo. Esos son los temas que tienen que estar y que están siendo actualmente discutidos, prestando atención al gerundio, incluidos porque la ESI excede y mucho lo que el gobierno nacional y la política nacional hizo.

Si vos pudieras fantasear contenidos actuales, ¿qué pondrías?

GM: En principio, y teniendo en cuenta el trabajo que más conozco, que es el de la formación docente y la escuela secundaria, para mí debería haber una discusión epistemológica en todas las disciplinas del currículum. Cada vez que voy a hacer una capacitación o la diplomatura, levantan la mano y me preguntan qué pasa con educación física, qué pasa con arte. La mirada transversal crítica y la epistemología que transforma esos saberes tiene que estar primero, estimulando que en las universidades y en los institutos de formación docente se genere conocimiento sobre esto. Aún hoy en 2020, yo no creo que haya un corpus de conocimientos acá para transmitir al sistema educativo que está allá. Hay una acumulación de conocimientos de este tipo en Historia, sí. Los hay en Lengua y Literatura, diría también. Hay una acumulación de críticas en educación física. Pero no hay experiencias, no hay un desarrollo curricular, hay crítica. Desde mi punto de vista, la experiencia curricular es también en acción, no solo en la lista de contenidos. Para mí, un eje duro es el de los contenidos curriculares. Otro eje duro, mucho más difícil aún, es que la ESI dialoga, interpela y cuestiona también el lugar docente. Siempre digo que hay una famosísima tríada pedagógica que es docente-estudiante-conocimiento. La ESI cuestiona esos tres polos: los estudiantes irrumpen con sus identidades, sus cuerpos sexuados y sus experiencias diversas, el conocimiento discutido epistemológicamente y los docentes en su formación. Pero también hay que repensar el lugar que tienen en la estructura escolar y la estructura escolar misma. El secundario, por ejemplo, tiene que cambiar. La ESI viene a discutir la división entre materias, la división dentro y fuera del aula, la división entre docentes y estudiantes. Porque es como informática, viste, a veces los pibes, las pibas, les pibis... saben más. A veces saben más, porque tienen experiencias. $Y$ hablo a aquí en general de la experiencia generacional. $Y$ esto interpela al sector docente. Hay algo de la estructura escolar que tiene que cambiar para alojar la ESI. Se trata de cambiar la mirada, la posición docente. No solo tienen que cambiar las personas, ya que hay personas resistentes y conservadoras, muchísimas, sino que estoy diciendo que tiene que cambiar la posición docente que es la del saber, y la de la hora cátedra, esta cosa tan fragmentada del día escolar. Ahí, la ESI más que como perspectiva y contenido, es la ESI discutiendo la estructura escolar. Pero para eso falta mucho.

Lo que sí puedo decir es que es una actual preocupación del Ministerio de Educación la de revisar y reformular la estructura de la escuela secundaria. Pensando, por ejemplo, que se curse por materia, en vez de cursar por año. Poder cambiar la gramática de la escuela secundaria en función de que las personas, sus deseos y sus conocimientos estén mejor valorados.

Nosotras nos preguntábamos, pensando en la ESI, qué pasa en la Educación Superior con la ESI. Tal vez esos problemas de la educación media se pueden pensar en Educación Superior.

GM: Sí, tal cual. Es igual. Yo diría incluso que es un poquito peor.

Sí, pensábamos en tus trabajos y tus producciones. Esta cuestión de pensar con perspectiva de género el trabajo docente. ¿Cómo juega ahí la ESI, y como se puede relacionar con los cuidados? Pensar la relación entre la academia y los cuidados es un debate pendiente que explota, y quizás la ESI podría abrir una puerta para pensar esto. 
GM: Yo creo que todo lo que incluye Superior tiene gramáticas diferentes. En los institutos terciarios, que dependen de los gobiernos provinciales, en última instancia hay una incorporación de materias. Por ejemplo, educación sexual, a veces anual. En la universidad, la misma lógica de la autonomía universitaria hace que seamos los actores y las actrices institucionales disputando poder para incluir perspectivas en los planes de estudios, para validar las investigaciones, la epistemología y las pedagogías feministas. Es una lucha que está en curso. Lo que puedo decir con alegría es que, en noviembre pasado, la Asociación de Facultades de Humanidades y Educación que nuclea a todos los decanos y decanas de Humanidades tuvo una reunión y se llegó a la conclusión de que como las facultades también forman docentes, (¡oh, descubrimiento!) tienen que incorporar la ESI como en toda la formación docente. Toda la asociación llegó a esa conclusión, no fui yo.

\section{¿Cómo fue ser decana en un mundo de decanos?}

GM: Yo fui decana de una facultad que conocía mucho, en la que milité mucho tiempo desde diferentes espacios, y fue un proceso del espacio político. En algún momento, el decano anterior, Hugo Trinchero, dijo: "esta facultad tiene que tener una decana, basta". Había otras mujeres candidatas, y por el espacio nuestro fui yo. Hubo un proceso institucional, no llegué a ser decana por una fuerza exógena, sino que fue una cuestión endógena. ¿Podría haber sido antes? Y, sí. ¿Debería haber sido antes? Y, sí. Pero bueno, los dispositivos micropolíticos de la construcción del poder existen, y también en una facultad súper crítica y que podrías decir, de "avanzada", los procesos de construcción de un liderazgo son largos. Yo ahora que cambié de escenario, estoy teniendo oportunidad de reflexionar mi manera de concebir la gestión. Creo que llevé adelante, también explícitamente, un modo de construcción feminista, o al menos de mujer feminista. Además, procurando apoyarme en los colectivos que me apoyaron: en los colectivos políticos y en mi propio espacio de investigación. Siempre tratando de mantener un proyecto por encima de los egos, de las personas, poniendo mucha fuerza en que haya proyectos políticos liderados por personas, y no solamente proyectos de las personas. Tal vez no tuve la oportunidad de sistematizar la experiencia, de pensarla, de escribirla. Pero me da la impresión de que puede haber formas de gestión no violentas. Hay muchos compañeros de nuestra facultad que tienen esta visión, pero creo que mi mirada y mi práctica de la construcción de poder fue tener apoyos de colectivos, y que esos colectivos son los que garantizan y fundamentan la práctica. Siempre me sentí emergente de un espacio y que representaba a las personas que representaba. Pero este es un proceso muy reciente y no tuve mucho tiempo para pensarlo.
En el transcurso de esta entrevista dijiste que deviniste peronista. Es interesante ese devenir peronista-feminista. Nos podés contar un poco más sobre este proceso.

GM: Yo venía de un pensamiento más de izquierda. Simpaticé en un momento de mi juventud con el troskismo de Zamora. Durante mucho tiempo estuve convencida que les troskes tenían razón, solo que lo que sostenían no se podía aplicar en la coyuntura. Pero también sentí una fascinación, primero de lejos y después cada vez más de cerca, de la forma de construcción y de ejercicio del poder en el peronismo, que comparto. Me parece que hay algunos sentidos que son los que orientan la acción, y después hay que hacerla. Dicen que el General afirmó: "Ios melones se acomodan mientras el camión marcha"; y yo creo que sí, que andando se acomodan los melones. Hay una osadía y una firmeza en la forma de ejercer el poder en el peronismo que a mí me fascinó.

De modo que el peronismo me fue fascinando y me terminó de fascinar con Cristina Fernández de Kirchner, que me enamoró directamente. Yo siempre fui, digamos, filoperonista, pero para reconocerme peronista fueron determinantes Néstor y Cristina. Cuando dijeron: "con los fondos buitres no sabemos qué vamos a hacer, pero no les vamos a pagar", fue determinante. Esa convicción que tal vez no tenés las cosas del todo claras, porque hay otras formas más "prolijas" de hacer las cosas, y lo digo en un tono peyorativo que es tener todo atado mientras el carro va pasando, porque si querés tener todo atado no hay una manera de hacer gestión. No hay manera de hacer si querés tener todas las certezas, algún riesgo hay que tomar. Hay algunas cuestiones en que lo que importa es el sentido, para dónde vas, a quién querés beneficiar, si vas por el lado de la democracia, si vas por el lado de la justicia. No es abstracto, es bien concreto. ¿Eso va para el lado de la justicia? Bueno, hagámoslo.

¿Cómo ves esta irrupción del feminismo en el peronismo? GM: Yo participé y soy coautora de un seminario sobre peronismo y feminismo que se hizo en el Instituto Patria, así que pensé bastante el tema. El feminismo y el peronismo estuvieron opuestos en vida de Evita. Hubo ahí una tensión que no se resolvió durante la vida de ella. Las relecturas posteriores y mi propia mirada desde esta perspectiva del feminismo popular, desde esta perspectiva de la praxis feminista y no solo de la declaración de ser feminista, a mí me lleva a pensar que Eva tuvo, en la década en la que vivió, una práctica feminista y que hizo por las mujeres y con las mujeres un avance en la construcción de una ciudadanía plena. Creo que fue determinante para la vida de las mujeres. Hay una edición de La razón de mi vida que tiene un prólogo mío, donde digo todo esto. Yo digo que si Evita viviera sería militante feminista, y abortera, 
¡las tendría todas! Para su época encarnó una mirada de avanzada. Si vos leés de manera literal La razón de mi vida te querés matar, porque la constante del amor (esa cosa con Perón todo el tiempo) es agotadora. Pero si leés lo que hizo, si ves lo que hizo, ves que no estaba nada sujeta a ese hombre ni a ningún otro. En todo caso, estaba ahí, coconduciendo desde otro lugar. De modo que desde mi punto de vista el feminismo hoy es un actor determinante.

¿En qué estás trabajando ahora?

GM: ¡En un montón de cosas! Básicamente en el Programa Progresar de apoyo a las trayectorias de estudiantes en situación más vulnerabilizada y proyectos que se refieren a convocar a los actores y a las organizaciones que hacen a lo educativo no escolar, pero que coadyuvan en el logro del derecho a la educación: centros de estudiantes, cooperadoras, organizaciones civiles, etc. Pongo este ejemplo. En nuestro país no hay jardines, no hay guarderías, no hay escuelas infantiles suficientes de o a 3 años, no hay cobertura para niños y niñas de cuatro años, y a veces ni siquiera de cinco. ¿Qué hizo el Ministerio de Desarrollo Social de la Nación durante el kirchnerismo?: centros de desarrollo infantil (CDI). ¿Qué hizo el Gobierno de la Ciudad?: centros de primera infancia (CPI). Estos CPIs son inaceptables, porque es inaceptable que la ciudad más rica del país no haya construido escuelas infantiles. En el resto del país fue una realidad que los movimientos sociales saldaron con jardines comunitarios, con personas no docentes. El sector educación trabajó para que desde el nacimiento sea considerado una unidad pedagógica, que es el nivel inicial. El momento actual nos requiere mirar a esas cuidadoras que piden reconocimiento y piden formación. Yo estoy trabajando en eso. El sector de educación sostiene, y con razón, que tienen que ser escuelas. Yo también creo que tienen que ser escuelas, y que tienen que ser maestras. Pero, ¿qué hacemos ahora? Hoy, en nuestro país empobrecido, tenemos alrededor de 4.000 instituciones que no son escuelas. En algún momento se votó una ley que se intenta cumplir que es sobre la supervisión pedagógica de las escuelas. Hoy vamos por la formación de esas cuidadoras que están en esos espacios, pero no necesariamente formación docente porque algunas no tienen formación secundaria, por ejemplo. ¿Por qué, espero, lo podremos hacer? Porque el movimiento feminista puso en el tapete los derechos de las mujeres trabajadoras que están ahí, y de las mujeres trabajadoras que dejan a sus hijes con esas trabajadoras para ir cuidar, a veces, a les hijes de otras mujeres trabajadoras. Y, también, porque hay que pensar los derechos infantiles en un mismo plano. No saben lo que cuesta ponerlos en un mismo plano, porque el argumento es "pero bueno, los derechos infantiles, esto es educación de primera y educación de segunda". Yo no quiero educación de segunda, pero pienso qué hacemos con lo que está. Podemos hablar de esto porque el movimiento feminista puso en la arena de la discusión política que esas mujeres que se dedican al cuidado deben ser reconocidas y formadas. Apostamos a logralo.

¡Gracias, compañeras!! 
